\title{
Predictive Control in Matrix Converters - Part I: Principles, Topologies and Applications
}

\author{
M. Rivera, Member, IEEE, P. Wheeler, Fellow Member, IEEE, and A. Olloqui, Student Member, IEEE,
}

\begin{abstract}
This paper presents an overview of the predictive control principles applied to matrix converters and also the different topologies where this control technique is applied. It will be shown that the predictive strategy is a promising alternative to control matrix converters due to its simplicity and flexibility to include additional aspects in the control being suitable for different industrial applications.
\end{abstract}

Index Terms-Matrix Converter, Direct Matrix Converter, Indirect Matrix Converter, Power Control, Predictive Control, Control Strategies, Sinusoidal Current, Voltage Control, AC-AC Conversion, Modulation Schemes

\begin{tabular}{|c|c|c|}
\hline \multicolumn{3}{|c|}{ NOMENCLATURE } \\
\hline $\mathbf{i}_{s}$ & Source current & {$\left[\begin{array}{lll}i_{s A} & i_{s B} & i_{s C}\end{array}\right]^{T}$} \\
\hline $\mathbf{v}_{s}$ & Source voltage & {$\left[\begin{array}{lll}v_{s A} & v_{s B} & v_{s C}\end{array}\right]^{T}$} \\
\hline $\mathbf{i}_{i}$ & Input current & {$\left[\begin{array}{lll}i_{A} & i_{B} & i_{C}\end{array}\right]^{T}$} \\
\hline $\mathbf{v}_{i}$ & Input voltage & {$\left[\begin{array}{lll}v_{A} & v_{B} & v_{C}\end{array}\right]^{T}$} \\
\hline$i_{d c}$ & dc-link current & \\
\hline$v_{d c}$ & dc-link voltage & \\
\hline $\mathbf{i}_{O}$ & Output current & {$\left[\begin{array}{lll}i_{a} & i_{b} & i_{c}\end{array}\right]^{T}$} \\
\hline $\mathbf{v}_{o}$ & Output voltage & {$\left[\begin{array}{lll}v_{a} & v_{b} & v_{c}\end{array}\right]^{T}$} \\
\hline $\mathbf{i}_{s}^{*}$ & Source current reference & {$\left[i_{s A}^{*} i_{s B}^{*} i_{s C}^{*}\right]^{T}$} \\
\hline $\mathbf{i}_{O}^{*}$ & Output current reference & {$\left[\begin{array}{lll}i_{a}^{*} & i_{b}^{*} & i_{c}^{*}\end{array}\right]^{T}$} \\
\hline $\mathbf{v}_{o}^{*}$ & Output voltage reference & {$\left[\begin{array}{lll}v_{a}^{*} & v_{b}^{*} & v_{c}^{*}\end{array}\right]^{T}$} \\
\hline$C_{f}$ & Input filter capacitor & \\
\hline$L_{f}$ & Input filter inductor & \\
\hline$R_{f}$ & Input filter resistor & \\
\hline$R_{L}$ & Load resistance & \\
\hline$L_{L}$ & Load inductance & \\
\hline
\end{tabular}

\section{INTRODUCTION}

The matrix converter (MC) is a simple and compact power circuit that directly connects the ac-source with any arbitrary ac-load without the need for large storage elements, making this topology suitable for many applications where weight and size are important issues. With this converter, generation of output voltage with different amplitude and frequency, sinusoidal input and output current waveforms, as well as operation with unity displacement power factor and regenerative capability are made possible. One challenge of MCs used to be the commutation of bidirectional switches but this issue has been solved with multi-step commutation techniques and the use of new technologies in power elements. Due to these characteristics, in recent years MCs have shown continuous and fast development related to the development of new topologies and control methods, including industrial applications with standard units for high and medium voltage using cascade connections [1]-[5].
Different modulation and control methods for MCs are found in the literature and also in the industry. As studied in [6], the most used techniques nowadays are Venturini, carrier-based pulse width modulation (PWM), space vector modulation (SVM) and direct torque control (DTC). Other methods that have been applied to MCs in specific applications are fuzzy control, neural networks and genetic algorithms. Predictive control has shown to be a very interesting alternative for control MCs, specially because the use of the discrete nature of power converters and its simplicity for implementation and intuitive approach. The main objective of this work is to provide a review of the main contributions and trends of predictive control in MCs: the topologies, the different control strategies, and the applications where it has been implemented.

The second part of this paper presents an overview of different control strategies and applications for MCs where predictive control techniques are applied.

\section{Mathematical Model of the MC}

The power topology of the MC is presented in Fig. 1. It consists of bidirectional switches to directly connect the input side with the load side without any intermediate dc-link storage element. An input filter is connected at the input side of the converter with two purposes [1]:

- To avoid over-voltage due to short-circuiting the impedance of the power supply, by cause of the fast commutation of currents $\mathbf{i}_{i}$.

- To eliminate high-frequency harmonics in the input currents $\mathbf{i}_{s}$.

Such as in each converter, the operation of the direct MC (DMC) is restricted to some operation constraints: the load current cannot be interrupted abruptly, due to

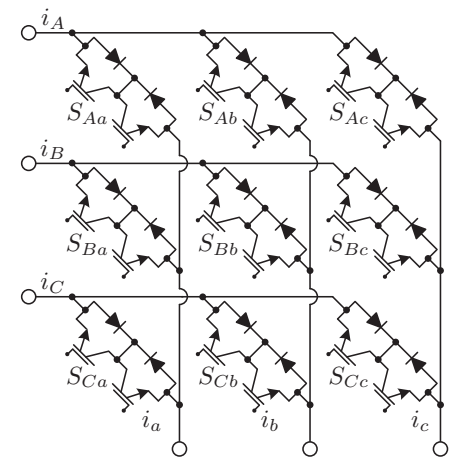

Fig. 1. Power topology of the conventional direct matrix converter. 


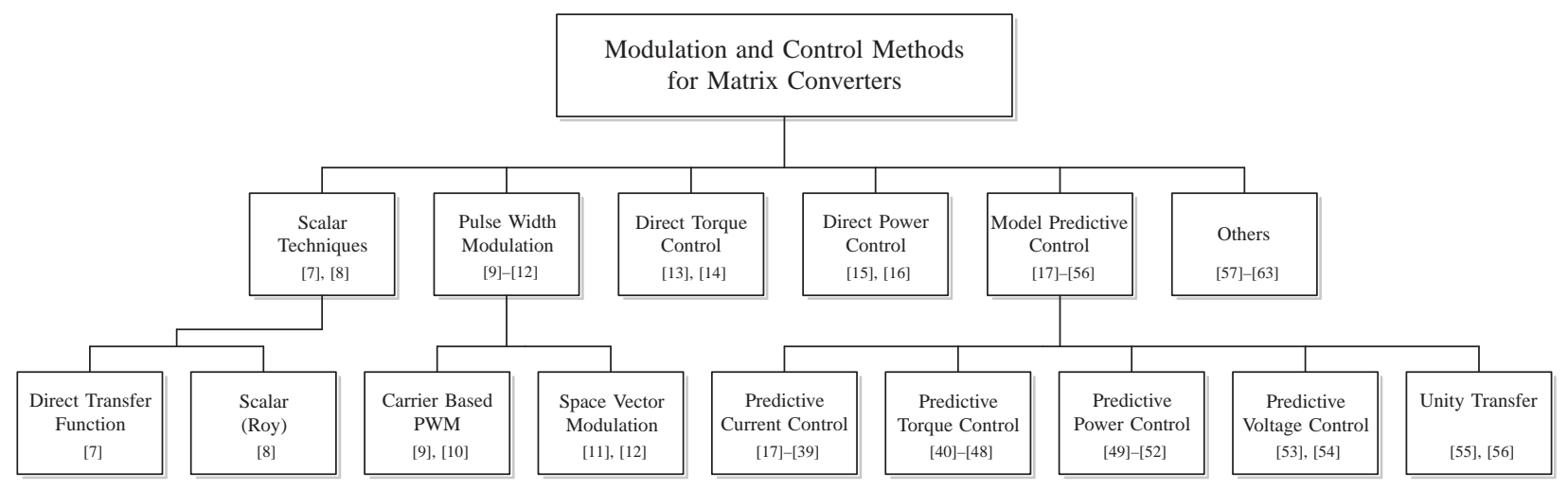

Fig. 2. Summary of modulation and control methods for matrix converters.

the inductive nature of the load, and the operation of the switches cannot short-circuit two input lines, owing to the presence of capacitors in the input filter. These restrictions can be expressed by:

$$
S_{A y}+S_{B y}+S_{C y}=1, \quad \forall y=a, b, c
$$

The relations between the input and output variables of the MC are given by:

$$
\begin{gathered}
\mathbf{v}_{o}=\mathbf{T}\left(S_{i j}\right) \mathbf{v}_{i} \\
\mathbf{i}_{i}=\mathbf{T}\left(S_{i j}\right)^{T} \mathbf{i}_{o}
\end{gathered}
$$

where $T$ is the instantaneous transfer matrix defined as:

$$
\mathbf{T}\left(S_{i j}\right)=\left[\begin{array}{ccc}
S_{A a} & S_{B a} & S_{C a} \\
S_{A b} & S_{B b} & S_{C b} \\
S_{A c} & S_{B c} & S_{C c}
\end{array}\right]
$$

Equations (3) and (4) are the basis of all modulation and control methods, which consist of selecting appropriate combinations of on and off switches to achieve the desired output voltages.

\section{Classical Modulation and Control TECHNIQUES FOR MCS}

Fig. 2 presents a summary of the more relevant modulation and control methods applied to MCs. As described in [6], these methods have different explanations and different levels of complexity, with a dynamic behavior acceptable for various applications. The first methods applied to MCs where Venturini and Roy's techniques which present a complex mathematical development [7], [8]. The pulse width modulation (PWM) technique is the simplest approach to modulate MCs [9]-[12]. The space vector modulation (SVM) [11], [12], [64]-[69] and direct torque control (DTC) [13], [14] are the most robust and used techniques for drives control in industrial applications but they are complex and not intuitive.

More advanced techniques, such as model predictive control, have recently been introduced to simplify the complexity of MC control with reliable and fast performance in both steady and transient states [17]-[56]. Other techniques that have been applied to MCs are direct power control [15], [16], fuzzy control, neural networks, genetic algorithms, among others [57]-[63].

\section{Principle of Predictive Control in MCs}

Model Predictive Control (MPC) is a relatively new control technique applied for the control of power electronic converters. This method utilizes the mathematical model of the controlled system in order to predict, at each sampling instant $k$, its behavior at $k+1$. For selecting an optimal state of the power converter, a cost function is defined. This function is composed of several constrains and control conditions. It usually contain the differences between the reference values and the predicted values of the variables being controlled. Many other components of this function represent specific constrains, such as limitation of the switching frequency, or other nonlinearities. As an example the predictive current control (PCC) for the direct matrix converter (DMC) is presented in this section.

The PCC scheme is shown in Fig. 3. It shows the switching state selection of the converter, which provides the controlled variables to the nearest respective references at the end of the sampling period. This control approach utilizes the converter and load models in order to predict the future value of the currents. A simple and representative model of the load can be expressed as:

$$
\frac{d \mathbf{i}_{o}}{d t}=\frac{1}{L_{o}} \mathbf{v}_{o}-\frac{R_{o}}{L_{o}} \mathbf{i}_{o}
$$

knowing the nature of the load (first order in our case), a first order discrete approximation allows predicting the future load current:

$$
\mathbf{i}_{o}(k+1)=\frac{T_{s} \mathbf{v}_{o}(k+1)+L_{o} \mathbf{i}_{o}(k)}{L_{o}+R_{o} T_{s}}
$$

where $T_{s}$ corresponds to the sampling time.

A cost function is defined in order to determine the error between the current references $\mathbf{i}_{o}^{*}$, and their respective current predictions $\mathbf{i}_{o}^{p}$, given by:

$$
g(k+1)=\left|i_{a}^{*}-i_{a}^{p}\right|+\left|i_{b}^{*}-i_{b}^{p}\right|+\left|i_{c}^{*}-i_{c}^{p}\right|
$$

As reported in [25]-[28], [31], [33]-[36], [70] this strategy performs well with a very good behavior in both steady and transient state showing to be a very good alternative to classical control strategies. 


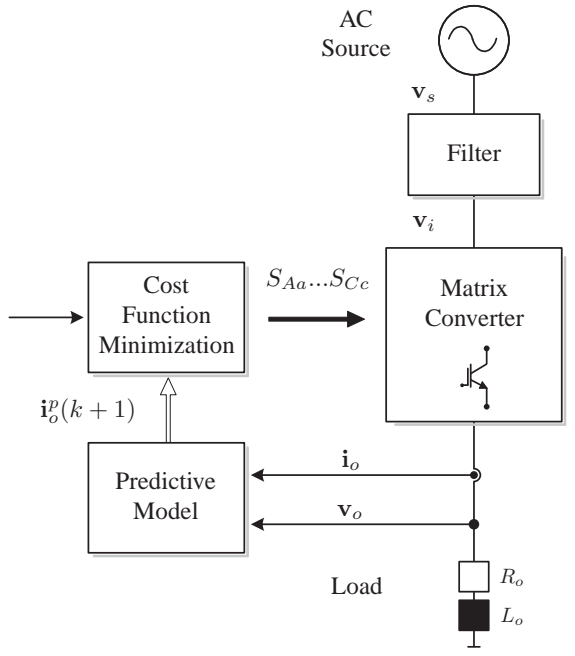

Fig. 3. Block diagram of the predictive current control strategy.

\section{Predictive Control in Different Topologies OF MATRIX CONVERTERS}

As presented in [2]-[4], there are several topologies of MCs. The main differences between them are given by the number of switches, operation constraints and applications. The most important advantages of these extensions are: the increment of output voltage control range and the reduction of the switching frequency harmonics, losses and common mode voltage. The most common and used topology where predictive control has been implemented is the direct matrix converter (DMC), shown in Fig. 1. One challenge of this converter is the safe commutation of the nine switches (eighteen IGBTs in total) and its modulation, which is very complex. Additionally, in the operation of a DMC with predictive control, a critical issue has been the high sampling frequency needed, but nowadays this problem has been solved due to the technological progress in fast and powerful microcontrollers. Many authors have used this converter in [18], [21], [23], [31]-[34], [36]-[38], [41], [42], [46], [47], [49], [53], [55], [70]-[72] to apply different techniques for a large number of applications. For this converter, twenty seven different switching states must be evaluated every sampling instant in order to select the one that minimizes the cost function. The current control on the output side of the converter is a very well studied issue, specially for motor drive and grid interconnection applications. Some aspects considered in the control of the DMC are the amplitude and phase control of the input currents in order to operate with unity, capacitive or inductive power factor. Another relevant issue that has been objective for study with predictive control, in consideration for the safe operation of the DMC, is the reduction of the distortion in the input currents produced by input filter resonances due to the commutation and several perturbations in the ac-supply. Due to the large number of power semiconductors of the DMC, some authors have studied also the increment of the efficiency of the converter by reducing the switching losses and

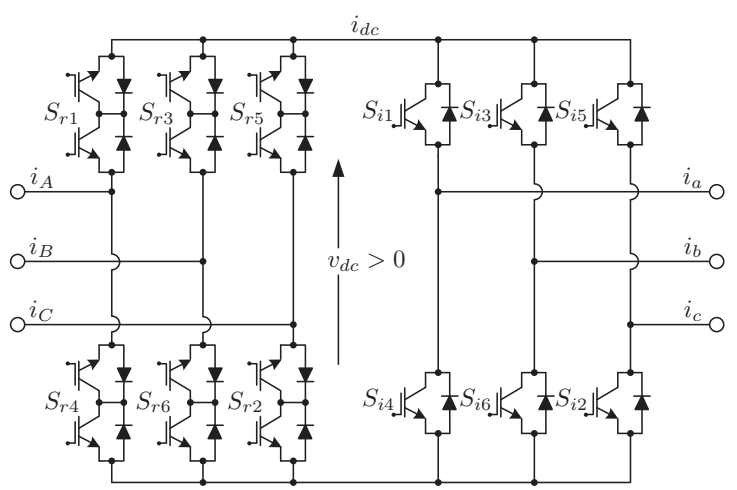

Fig. 4. Conventional indirect matrix converter (common collector).

frequency. The most important contribution in all the works done with predictive control, is the simplicity for the safe operation of the DMC, eliminating complex transformations and modulations which are required in PWM and SVM techniques and also the capability to use all the available switching vectors of the converter which is not possible with classical techniques, making this topology an effective alternative when size and weight are important requirements. In [53], [54], are proposed two predictive controllers for a single-phase MC (SPMC) where the topology, along with a resonant circuit, a HFtransformer and a diode bridge, is used as a dc power supply for high-power radio frequency (RF) applications, mainly used in some industrial applications such as microwaves for mineral extraction, medical imaging, television transmission and also research applications (mainly particle physics research). Additionally, this converter is meant to be used in cascaded configurations for high power applications which are connected to the ac source by a common multi-pulse transformer [5]. In [73], a recent work has been published to control a SPMC where is also discussed a possible use of this type of converters in grid interconnection systems, where a medium frequency transformer is required to isolate the grids. In [17], an interesting application of predictive control is found for a three-to-five leg DMC, where complex modulations and three-dimensional transformations are avoided with only a predictive model of the load and source currents. The main challenge in the implementation of predictive control in this converter is the large number of available switching states (243 valid switching states) that must be taking into consideration which requires a high computational cost. The indirect matrix converter (IMC) shown in Fig. 4 is other topology where important contributions of predictive control have been done, such as reported in [19], [22], [24]-[28], [30], [35], [39], [43]-[45], [61]. The IMC, in contrast to the DMC, presents a more simple modulation and commutation known as zero dclink current strategy [5], [39], which allows to reduce the commutation losses and thus increase the efficiency of the converter. The main challenge in this topology is to ensure a positive dc-link voltage while working with a unity displacement power factor at the input side [22], [25]- 
[28], [30], [35], [39], [43], [45]. For this converter there are seventy-two valid switching states to be evaluated in the cost function each sampling time, nine given by the rectifier side and eight by the inverter side. But as only a positive dc-link voltage is allowed at any time, the number of valid switching states in the rectifier side that can be applied at any specific time are reduced to only three, thus, the total number of valid switching states that are evaluated in the cost function are reduced to twenty-four. Similarly to the DMC, predictive control in an IMC has been implemented for motor drives in military, aerospace and renewable energy applications where size and weight are relevant issues [24], [61]. Moreover the mitigation of resonances on the input filter due to perturbations of the AC source and due to the commutations of the switches has been considered [22], [25], [27], [30]. The utilization of an IMC as a shunt active power filter operating with a predictive current control strategy was proposed in [19], where the output reference currents are obtained using P-Q theory. An important aspect observed in [19] was the fast dynamic response of the predictive controller, allowing to obtain almost sinusoidal source currents, eliminating the effect of non-linear load currents. As reviewed in [2], [4], there are different topologies derived from the IMC with reduced number of switches and switching states for specific applications. Predictive control has also been applied to these topologies such as reported in [20], [29], [40], [50], [56], [74], where are used a sparse matrix converter (SMC) (Fig. 5), ultra sparse matrix converter (USMC), or with extended number of switches as the IMC with four and six legs, and a hybrid indirect matrix converter (HIMC) (Fig. 6), respectively. As shown in Fig. 5, the SMC utilizes twelve IGBTs and thirty diodes. This reduction in terms of switches allow a more simple topology functionally equivalent to the conventional IMC. Again, the main challenges for the safe operation of this converter are to generate maximum voltage in the DC-link while maintaining sinusoidal currents and unity displacement input power factor [20]. Special attention must be taken into consideration while working with this converter because, as similar to the IMC, it is necessary synchronize the commutation of the rectifier and inverter switches. The inverter must be switched into a freewheeling state in order to commutate the rectifier at zero current in the DC-link. In [20], the predictive technique is mixed with a space vector pulse with modulation (SVPWM) allowing the operation with fixed switching frequency. In this particular application only the load current is operated by the predictive controller avoiding the use of linear current controllers. As only the load currents are controlled by the predictive algorithm only eight valid switching states are evaluated in the cost function and thus the optimal selected switching vector generates the reference voltage for the modulator. The PWM technique is in charge to ensure unity power factor operation on the input side while following the voltage reference imposed by the predictive controller. A modified topology of an ultra sparse matrix converter (USMC) is

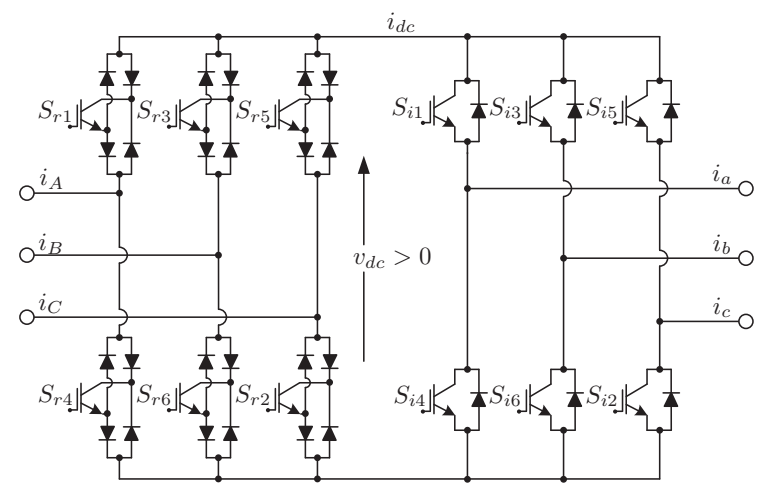

Fig. 5. Sparse matrix converter.

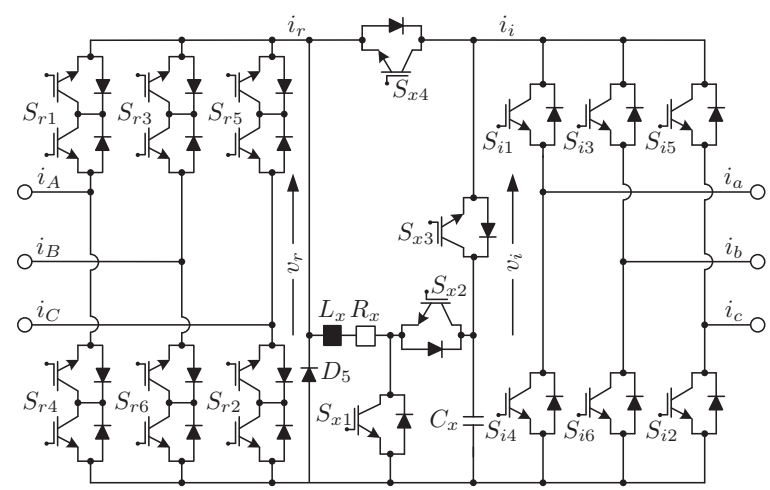

Fig. 6. Hybrid indirect matrix converter.

proposed in [50]. The main difference between this new topology and the classical USMC is that in the proposed architecture, the output stage has bidirectional switches, allowing the transfer of energy from the DC-link to the load and viceversa. Here, the authors used predictive control to handle the electrical power of the micro-turbine grid by the manipulation of the fuel flow, being very effective for both small step changes and large random changes. In [74] predictive control has been applied to a four-leg indirect matrix converter (4L-IMC). The control objectives are load current control and minimization of the instantaneous reactive input power or also the load voltage control by including an $L C$ filter in the output side [29]. As in the previously analyzed indirect matrix converter topologies, the main challenge is given by the safe commutation of the switches in both rectifier and inverter stages. Additionally, the large number of IGBTs and thus the large number of available switching states, make this converter difficult to control requiring 3D modulation techniques which are very complex and non intuitive to understand. One relevant aspect of predictive control is its simplicity and intuitive concept allowing a very simple control for this kind of power converter topologies. As it has been demonstrated in these papers, the predictive strategy performs well with a good performance in both steady and transient states, using only the mathematical model of the converter and load, with all the control objectives merged in only one cost function. In [40] a predictive control for a multi-drive system has 
been proposed to control two induction machines feeded by a six-leg IMC. Multi-drive systems are very useful nowadays in aerospace applications, exploration and military vehicles, tractors, mining trucks, conveyor belts, among others. Traditionally these systems have the same number of converters than loads (generally ac motors), but recently it has been proposed the use of multi-phase matrix converters to feed several induction machines (IM) with a single converter and thus, to reduce the weight and size of the multi-drive system. The main challenges of multi-phase matrix converters are the increment of the available switching states that can be applied to the converter and must be taking into consideration every sampling time for the optimization algorithm. But also is very relevant to ensure a correct synchronization in the commutation of the switches in order to operate the converter correctly. It is well known that a high sampling frequency is required for a good performance of the predictive control in its implementation. But, is necessary to decrease the sampling frequency in order to be able to evaluate all the valid switching states at every sampling instant which make worse the control behavior. In order to solve this aspect, some recent studies have considered some redundances in the model and switching states, in order to reduce the number of states under evaluation. Despite this, in [40] it has been demonstrated the feasibility for implementation of this control strategy, obtaining an effective control of both IMs operating at the same speed but at different load torque. Also recent work on IMC-based topologies redefine the valid states of the rectifier side whether the maximum dc-link voltage at any specific time is needed or not, reducing to two thirds the total number of valid switching states that are evaluated in the cost function. As highlighted in this paper, the MC presents different advantages in term of size and weight, allowing the operation with sinusoidal source and load currents, regeneration capability among others, but despite all the rewards, there exists two main disadvantages in the MC topology (as long as the maximum voltage transfer ratio is not reached [75]): the output voltage is limited to $86 \%$ of the input, and secondly, any perturbation in the supply deteriorates the quality of the load side, due to the absence of storage elements.

In order to solve this issue, in [56] has been proposed the implementation of a hybrid power converter which connects an auxiliary voltage source in the dc-link of the IMC, obtaining unity voltage transfer capability even under severe distortions in the source voltage as shown in Fig. 6. The main challenges of this topology are the control of the input side and the commutation of the switches in the rectifier side as well as the control of the auxiliary circuit connected to the dc-link and finally the control on the output side of the converter.

A predictive current control strategy is proposed in this work for the auxiliary voltage source, where the current reference is given by a PI linear controller and the predictive control generates the duty cycle for the pulsewidth modulator. With this predictive controller and the proposed architecture is ensured balanced power in the converter and unity voltage ratio.

In summary, in all the previous cases, predictive control demonstrated a very good performance, being a very simple method for implementation. Predictive control has been implemented in several topologies of MCs to overcome disadvantages of the MC technology over the twolevel voltage dc-link back-to-back converter (V-BBC) in specific applications, demonstrating to be a very flexible and useful technique, introducing a new and promising alternative for electric power conversion for low-voltage and low-power $(\leq 100 \mathrm{~kW})[75]$.

\section{CONCLUSIONS}

The main contribution of this paper has been to present an overview of different topologies of matrix converters where predictive control techniques are applied. A detailed description about the constraints, limitations and challenges of each topology for the implementation of predictive control have been presented. Based on the review given by the authors, predictive control has a very high impact in the control of matrix converters, due its simplicity and intuitive approach, making this control strategy a real alternative in power electronics.

\section{ACKNOWLEDGMENTS}

This publication was made possible by the Newton Picarte Project EPSRC: EP/N004043/1: New Configurations of Power Converters for Grid Interconnection Systems / CONICYT DPI20140007.

\section{REFERENCES}

[1] P. W. Wheeler, J. Rodriguez, J. C. Clare, L. Empringham, and A. Weinstein, "Matrix converters: a technology review," Industrial Electronics, IEEE Transactions on, vol. 49, no. 2, pp. 276-288, 2002.

[2] J. W. Kolar, T. Friedli, F. Krismer, and S. D. Round, "The essence of three-phase ac/ac converter systems," in Power Electronics and Motion Control Conference, 2008. EPE-PEMC 2008. 13th, 1-3 Sept. 2008 2008, pp. 27-42.

[3] P. Wheeler, L. Xu, L. Meng Yeong, L. Empringham, C. Klumpner, and J. Clare, "A review of multi-level matrix converter topologies," in Power Electronics, Machines and Drives, 2008. PEMD 2008. 4th IET Conference on, 2-4 April 2008 2008, pp. 286-290.

[4] T. Friedli and J. W. Kolar, "Comprehensive comparison of threephase ac-ac matrix converter and voltage dc-link back-to-back converter systems," in Power Electronics Conference (IPEC), 2010 International, 21-24 June 2010 2010, pp. 2789-2798.

[5] J. W. Kolar, T. Friedli, J. Rodriguez, and P. W. Wheeler, "Review of three-phase pwm ac-ac converter topologies," Industrial Electronics, IEEE Transactions on, vol. 58, no. 11, pp. 4988-5006, 2011.

[6] J. Rodriguez, M. Rivera, J. W. Kolar, and P. W. Wheeler, "A review of control and modulation methods for matrix converters," Industrial Electronics, IEEE Transactions on, vol. 59, no. 1, pp. 58-70, 2012.

[7] S. Lopez Arevalo, P. Zanchetta, P. W. Wheeler, A. Trentin, and L. Empringham, "Control and implementation of a matrixconverter-based ac ground power-supply unit for aircraft servicing," Industrial Electronics, IEEE Transactions on, vol. 57, no. 6, pp. 2076-2084, 2010.

[8] G. Roy and G. E. April, "Cycloconverter operation under a new scalar control algorithm," in Power Electronics Specialists Conference, 1989. PESC '89 Record., 20th Annual IEEE, 26-29 Jun 1989 1989, pp. 368-375 vol.1. 
[9] T. D. Nguyen and L. Hong-Hee, "Generalized carrier-based pwm method for indirect matrix converters," in Sustainable Energy Technologies (ICSET), 2012 IEEE Third International Conference on, 24-27 Sept. 2012 2012, pp. 223-228.

[10] P. G. Potamianos, E. D. Mitronikas, and A. N. Safacas, "Opencircuit fault diagnosis for matrix converter drives and remedial operation using carrier-based modulation methods," Industrial Electronics, IEEE Transactions on, vol. 61, no. 1, pp. 531-545, 2014.

[11] T. D. Nguyen and H. H. Lee, "A new svm method for an indirect matrix converter with common-mode voltage reduction," Industrial Informatics, IEEE Transactions on, vol. PP, no. 99, pp. 1-1, 2013.

[12] W. Xingwei, L. Hua, S. Hongwu, and F. Bo, "A research on space vector modulation strategy for matrix converter under abnormal input-voltage conditions," Industrial Electronics, IEEE Transactions on, vol. 59, no. 1, pp. 93-104, 2012.

[13] D. Xiao and M. F. Rahman, "A novel sensorless direct torque control for matrix converter-fed ipm synchronous machine," in Electrical Machines and Systems (ICEMS), 2011 International Conference on, 20-23 Aug. 2011 2011, pp. 1-6.

[14] A. Yousefi-Talouki, S. A. Gholamian, M. Yousefi-Talouki, R. Ilka, and A. Radan, "Harmonic elimination in switching table-based direct torque control of five-phase pmsm using matrix converter," in Humanities, Science and Engineering Research (SHUSER), 2012 IEEE Symposium on, 24-27 June 2012 2012, pp. 777-782.

[15] T. Noguchi and A. Sato, "Direct power control based indirect ac to ac power conversion system," in Power Electronics and Applications, 2009. EPE '09. 13th European Conference on, 810 Sept. 2009 2009, pp. 1-8.

[16] J. Monteiro, J. F. Silva, S. F. Pinto, and J. Palma, "Matrix converter-based unified power-flow controllers: Advanced direct power control method," Power Delivery, IEEE Transactions on, vol. 26, no. 1, pp. 420-430, 2011.

[17] S. K. M. Ahmed, A. Iqbal, H. Abu-Rub, and P. Cortes, "Model predictive control of a three-to-five phase matrix converter," in Predictive Control of Electrical Drives and Power Electronics (PRECEDE), 2011 Workshop on, 14-15 Oct. 2011 2011, pp. 3639.

[18] J. D. Dasika and M. Saeedifard, "An on-line fault detection and a post-fault strategy to improve the reliability of matrix converters," in Applied Power Electronics Conference and Exposition (APEC), 2013 Twenty-Eighth Annual IEEE, 17-21 March 2013 2013, pp. 1185-1191.

[19] A. A. Heris, E. Babaei, and S. H. Hosseini, "A new shunt active power filter based on indirect matrix converter," in Electrical Engineering (ICEE), 2012 20th Iranian Conference on, 15-17 May 2012 2012, pp. 581-586.

[20] E. Lee, L. Kyo-Beum, L. Jae-Sik, L. Youngil, and S. Joong-Ho, "Predictive current control for a sparse matrix converter," in Power Electronics and Motion Control Conference (IPEMC), 2012 7th International, vol. 1, 2-5 June 2012 2012, pp. 36-40.

[21] F. Morel, J. M. Retif, L.-S. Xuefang, B. Allard, and P. Bevilacqua, "A predictive control for a matrix converter-fed permanent magnet synchronous machine," in Power Electronics Specialists Conference, 2008. PESC 2008. IEEE, 15-19 June 2008 2008, pp. $15-21$.

[22] M. Rivera, P. Correa, J. Rodriguez, I. Lizama, and J. Espinoza, "Predictive control of the indirect matrix converter with active damping," in Power Electronics and Motion Control Conference, 2009. IPEMC '09. IEEE 6th International, 17-20 May 2009 2009, pp. $1738-1744$.

[23] M. Rivera, P. Correa, J. Rodriguez, I. Lizama, J. Espinoza, and C. Rojas, "Predictive control with active damping in a direct matrix converter," in Energy Conversion Congress and Exposition, 2009. ECCE 2009. IEEE, 20-24 Sept. 2009 2009, pp. 3057-3062.

[24] M. Rivera, J. L. Elizondo, M. E. Macias, O. M. Probst, O. M. Micheloud, J. Rodriguez, C. Rojas, and A. Wilson, "Model predictive control of a doubly fed induction generator with an indirect matrix converter," in IECON 2010 - 36th Annual Conference on IEEE Industrial Electronics Society, 7-10 Nov. 2010 2010, pp. 2959-2965.

[25] M. Rivera, J. Rodriguez, W. Bin, J. R. Espinoza, and C. A. Rojas, "Current control for an indirect matrix converter with filter resonance mitigation," Industrial Electronics, IEEE Transactions on, vol. 59, no. 1, pp. 71-79, 2012.

[26] M. Rivera, J. Rodriguez, J. Espinoza, and W. Bin, "Reduction of common-mode voltage in an indirect matrix converter with imposed sinusoidal input/output waveforms," in IECON 2012 38th Annual Conference on IEEE Industrial Electronics Society, 25-28 Oct. 2012 2012, pp. 6105-6110.

[27] M. Rivera, J. Rodriguez, J. R. Espinoza, and H. Abu-Rub, "Instantaneous reactive power minimization and current control for an indirect matrix converter under a distorted ac supply," Industrial Informatics, IEEE Transactions on, vol. 8, no. 3, pp. 482-490, 2012.

[28] M. Rivera, J. Rodriguez, J. R. Espinoza, T. Friedli, J. W. Kolar, A. Wilson, and C. A. Rojas, "Imposed sinusoidal source and load currents for an indirect matrix converter," Industrial Electronics, IEEE Transactions on, vol. 59, no. 9, pp. 3427-3435, 2012.

[29] M. Rivera, J. Rodriguez, C. Garcia, R. Pena, and J. Espinoza, "A simple predictive voltage control method with unity displacement power factor for four-leg indirect matrix converters," in Power Electronics and Motion Control Conference (EPE/PEMC), 2012 15th International, 4-6 Sept. 2012 2012, pp. DS2c.5-1-DS2c.56.

[30] M. Rivera, J. Rodriguez, M. Lopez, and J. Espinoza, "Control of an induction machine fed by an indirect matrix converter with unity displacement power factor operating with an unbalanced ac-supply," in Power Electronics and Motion Control Conference (EPE/PEMC), 2012 15th International, 4-6 Sept. 2012 2012, pp. DS2c.4-1-DS2c.4-8.

[31] M. Rivera, J. Rodriguez, P. W. Wheeler, C. A. Rojas, A. Wilson, and J. R. Espinoza, "Control of a matrix converter with imposed sinusoidal source currents," Industrial Electronics, IEEE Transactions on, vol. 59, no. 4, pp. 1939-1949, 2012.

[32] M. Rivera, C. Rojas, Rodri, x, J. guez, P. Wheeler, W. Bin, and J. R. Espinoza, "Predictive current control with input filter resonance mitigation for a direct matrix converter,' Power Electronics, IEEE Transactions on, vol. 26, no. 10, pp. 2794-2803, 2011.

[33] M. Rivera, C. Rojas, J. Rodriguez, and J. Espinoza, "Methods of source current reference generation for predictive control in a direct matrix converter," Power Electronics, IET, vol. 6, no. 5, 2013.

[34] J. Rodriguez, J. Espinoza, M. Rivera, F. Villarroel, and C. Rojas, "Predictive control of source and load currents in a direct matrix converter," in Industrial Technology (ICIT), 2010 IEEE International Conference on, 14-17 March 2010 2010, pp. 1826-1831.

[35] J. Rodriguez, J. Kolar, J. Espinoza, M. Rivera, and C. Rojas, "Predictive current control with reactive power minimization in an indirect matrix converter," in Industrial Technology (ICIT), 2010 IEEE International Conference on, 14-17 March 2010 2010, pp. 1839-1844.

[36] C. Rojas, M. Rivera, J. Rodriguez, A. Wilson, J. Espinoza, F. Villarroel, and P. Wheeler, "Predictive control of a direct matrix converter operating under an unbalanced ac source," in Industrial Electronics (ISIE), 2010 IEEE International Symposium on, 4-7 July 2010 2010, pp. 3159-3164.

[37] R. Vargas, U. Ammann, and J. Rodriguez, "Predictive approach to increase efficiency and reduce switching losses on matrix converters," Power Electronics, IEEE Transactions on, vol. 24, no. 4, pp. 894-902, 2009.

[38] R. Vargas, J. Rodriguez, U. Ammann, and P. W. Wheeler, "Predictive current control of an induction machine fed by a matrix converter with reactive power control," Industrial Electronics, IEEE Transactions on, vol. 55, no. 12, pp. 4362-4371, 2008.

[39] P. Correa, J. Rodriguez, M. Rivera, J. R. Espinoza, and J. W. Kolar, "Predictive control of an indirect matrix converter," Ieee Transactions on Industrial Electronics, vol. 56, no. 6, pp. 18471853, June 2009, iEEE Trans. Ind. Electron.

[40] M. Lopez, M. Rivera, C. Garcia, J. Rodriguez, R. Pena, J. Espinoza, and P. Wheeler, "Predictive torque control of a multi-drive system fed by a six-leg indirect matrix converter," in Industrial Technology (ICIT), 2013 IEEE International Conference on, 2528 Feb. 2013 2013, pp. 1642-1647.

[41] C. Ortega, A. Arias, and J. Espina, "Predictive vector selector for direct torque control of matrix converter fed induction motors," in Industrial Electronics, 2009. IECON '09. 35th Annual Conference of IEEE, 3-5 Nov. 2009 2009, pp. 1240-1245.

[42] C. Ortega, A. Arias, and et al., "Predictive direct torque control of matrix converter fed permanent magnet synchronous machines," in Industrial Electronics (ISIE), 2010 IEEE International Symposium on, 4-7 July 2010 2010, pp. 1451-1455.

[43] J. Rodriguez, J. Kolar, and et al., "Predictive torque and flux control of an induction machine fed by an indirect matrix converter 
with reactive power minimization," in Industrial Electronics (ISIE), 2010 IEEE International Symposium on, 4-7 July 2010 2010, pp. 3177-3183.

[44] J. Rodriguez, J. Kolar, J. Espinoza, M. Rivera, and C. Rojas, "Predictive torque and flux control of an induction machine fed by an indirect matrix converter," in Industrial Technology (ICIT), 2010 IEEE International Conference on, 14-17 March 2010 2010, pp. 1857-1863.

[45] S. M. M. Uddin, S. Mekhilef, M. Rivera, and J. Rodriguez, "A fcs-mpc of an induction motor fed by indirect matrix converter with unity power factor control," in Industrial Electronics and Applications (ICIEA), 2013 8th IEEE Conference on, 19-21 June 2013 2013, pp. 1769-1774.

[46] R. Vargas, U. Ammann, B. Hudoffsky, J. Rodriguez, and P. Wheeler, "Predictive torque control of an induction machine fed by a matrix converter with reactive input power control," Power Electronics, IEEE Transactions on, vol. 25, no. 6, pp. 1426-1438, 2010.

[47] R. Vargas, M. Rivera, J. Rodriguez, J. Espinoza, and P. Wheeler, "Predictive torque control with input pf correction applied to an induction machine fed by a matrix converter," in Power Electronics Specialists Conference, 2008. PESC 2008. IEEE, 15-19 June 2008 2008, pp. 9-14.

[48] L. Zakaria and K. Barra, "Predictive direct torque and flux control of an induction motor drive fed by a direct matrix converter with reactive power minimization," in Networking, Sensing and Control (ICNSC), 2013 10th IEEE International Conference on, 10-12 April 2013 2013, pp. 34-39.

[49] P. Gamboa, J. F. Silva, S. F. Pinto, and E. Margato, "Predictive optimal matrix converter control for a dynamic voltage restorer with flywheel energy storage," in Industrial Electronics, 2009. IECON '09. 35th Annual Conference of IEEE, 3-5 Nov. 2009 2009, pp. 759-764.

[50] M. Ortega, F. Jurado, and J. Carpio, "Control of indirect matrix converter with bidirectional output stage for micro-turbine," Power Electronics, IET, vol. 5, no. 6, pp. 659-668, 2012.

[51] S. Yusoff, L. De Lillo, P. Zanchetta, and P. Wheeler, "Predictive control of a direct ac/ac matrix converter power supply under nonlinear load conditions," in Power Electronics and Motion Control Conference (EPE/PEMC), 2012 15th International, 4-6 Sept. 2012 2012, pp. DS3c.4-1-DS3c.4-6.

[52] S. Yusoff, L. De Lillo, P. Zanchetta, P. Wheeler, P. Cortes, and J. Rodriguez, "Predictive control of a direct ac/ac matrix converter for power supply applications," in Power Electronics, Machines and Drives (PEMD 2012), 6th IET International Conference on, 27-29 March 2012 2012, pp. 1-6.

[53] D. J. Cook, M. Catucci, P. W. Wheeler, J. C. Clare, J. S. Przybyla, and B. R. Richardson, "Development of a predictive controller for use on a direct converter for high-energy physics applications," Industrial Electronics, IEEE Transactions on, vol. 55, no. 12, pp. 4325-4334, 2008.

[54] E. F. Reyes, A. J. Watson, J. C. Clare, and P. W. Wheeler, "Comparison of predictive control strategies for direct resonant high voltage dc power supply," in Power Electronics, Machines and Drives (PEMD 2012), 6th IET International Conference on, 27-29 March 2012 2012, pp. 1-6.

[55] R. Vargas, J. Rodriguez, C. Rojas, and P. Wheeler, "Predictive current control applied to a matrix converter: An assessment with the direct transfer function approach," in Industrial Technology (ICIT), 2010 IEEE International Conference on, 14-17 March 2010 2010, pp. 1832-1838.

[56] T. Wijekoon, C. Klumpner, P. Zanchetta, and P. W. Wheeler, "Implementation of a hybrid ac-ac direct power converter with unity voltage transfer," Power Electronics, IEEE Transactions on, vol. 23, no. 4, pp. 1918-1926, 2008.

[57] L. Hong Hee, D. Phan Quoc, P. Le Minh, and K. Le Dinh, “A new artificial neural network controller for direct control method for matrix converters," in Power Electronics and Drive Systems, 2009. PEDS 2009. International Conference on, 2-5 Nov. 2009 2009, pp. 434-439.

[58] H. Karaca, R. Akkaya, and H. Dogan, "A novel compensation method based on fuzzy logic control for matrix converter under distorted input voltage conditions," in Electrical Machines, 2008. ICEM 2008. 18th International Conference on, 6-9 Sept. 2008 2008, pp. $1-5$.

[59] P. Zanchetta, J. C. Clare, P. Wheeler, D. Katsis, M. Bland, and L. Empringham, "Control design of a three-phase matrix converter mobile ac power supply using genetic algorithms," in Power Electronics Specialists Conference, 2005. PESC '05. IEEE 36th, 16-16 June 2005 2005, pp. 2370-2375.

[60] P. Zanchetta, M. Sumner, J. C. Clare, and P. W. Wheeler, "Control of matrix converters for ac power supplies using genetic algorithms," in Industrial Electronics, 2004 IEEE International Symposium on, vol. 2, 4-7 May 2004 2004, pp. 1429-1433 vol. 2.

[61] C. F. Calvillo, F. Martell, J. L. Elizondo, A. Avila, M. E. Macias, M. Rivera, and J. Rodriguez, "Rotor current fuzzy control of a dfig with an indirect matrix converter," in IECON 2011 - 37th Annual Conference on IEEE Industrial Electronics Society, 7-10 Nov. 2011 2011, pp. 4296-4301.

[62] T. S. Sivarani, S. J. Jawhar, and C. A. Kumar, "Novel intelligent hybrid techniques for speed control of electric drives fed by matrix converter," in Computing, Electronics and Electrical Technologies (ICCEET), 2012 International Conference on, 21-22 March 2012 2012, pp. 466-471.

[63] W. Xiaohong, G. Quanxue, and T. Lianfang, "A novel adaptive fuzzy control for output voltage of matrix converter," in Power Electronics and Motion Control Conference (IPEMC), 2012 7th International, vol. 1, 2-5 June 2012 2012, pp. 53-58.

[64] F. Bradaschia, E. Ibarra, J. Andreu, I. Kortabarria, E. Ormaetxea, and M. Cavalcanti, "Matrix converter: Improvement of the space vector modulation via a new double-sided generalized scalar pwm," in Industrial Electronics, 2009. IECON '09. 35th Annual Conference of IEEE, 3-5 Nov. 2009 2009, pp. 4511-4516.

[65] R. Cardenas, Pe, x00F, R. a, P. Wheeler, and J. Clare, "Experimental validation of a space-vector-modulation algorithm for four-leg matrix converters," Industrial Electronics, IEEE Transactions on, vol. 58, no. 4, pp. 1282-1293, 2011.

[66] D. Casadei, G. Serra, A. Tani, and L. Zarri, "Optimal use of zero vectors for minimizing the output current distortion in matrix converters," Industrial Electronics, IEEE Transactions on, vol. 56, no. 2, pp. 326-336, 2009.

[67] M. Jussila and H. Tuusa, "Comparison of simple control strategies of space-vector modulated indirect matrix converter under distorted supply voltage," Power Electronics, IEEE Transactions on, vol. 22, no. 1, pp. 139-148, 2007.

[68] H. M. Nguyen, L. Hong-Hee, and C. Tae-Won, "Input power factor compensation algorithms using a new direct-svm method for matrix converter," Industrial Electronics, IEEE Transactions on, vol. 58, no. 1, pp. 232-243, 2011.

[69] A. M. Bozorgi, M. Monfared, and H. R. Mashhadi, "Optimum switching pattern of matrix converter space vector modulation," in Computer and Knowledge Engineering (ICCKE), 2012 2nd International eConference on, 18-19 Oct. 2012 2012, pp. 89-93.

[70] M. Rivera, A. Wilson, C. A. Rojas, J. Rodriguez, J. R. Espinoza, P. W. Wheeler, and L. Empringham, "A comparative assessment of model predictive current control and space vector modulation in a direct matrix converter," Industrial Electronics, IEEE Transactions on, vol. 60, no. 2, pp. 578-588, 2013.

[71] F. Villarroel, J. Espinoza, C. Rojas, C. Molina, and E. Espinosa, "A multiobjective ranking based finite states model predictive control scheme applied to a direct matrix converter," in IECON 2010 36th Annual Conference on IEEE Industrial Electronics Society, 7-10 Nov. 2010 2010, pp. 2941-2946.

[72] F. Villarroel, J. Espinoza, C. Rojas, C. Molina, and J. Rodriguez, "Application of fuzzy decision making to the switching state selection in the predictive control of a direct matrix converter," in IECON 2011 - 37th Annual Conference on IEEE Industrial Electronics Society, 7-10 Nov. 2011 2011, pp. 4272-4277.

[73] M. Rivera, J. Munoz, C. Baier, J. Rodriguez, J. Espinoza, V. Yaramasu, B. Wu, and P. Wheeler, "A simple predictive current control of a single-phase matrix converter," in 4th IEEE International Conference on Power Engineering, Energy and Electrical Drives, POWERENG (2013, Turkey), 13-17 May 20132013.

[74] M. Rivera, I. Contreras, J. Rodriguez, R. Pena, and P. Wheeler, "A simple current control method with instantaneous reactive power minimization for four-leg indirect matrix converters," in Power Electronics and Applications (EPE 2011), Proceedings of the 2011-14th European Conference on, 2011, pp. 1-9.

[75] T. Friedli, J. W. Kolar, J. Rodriguez, and P. W. Wheeler, "Comparative evaluation of three-phase ac-ac matrix converter and voltage dc-link back-to-back converter systems," Industrial Electronics, IEEE Transactions on, vol. 59, no. 12, pp. 4487-4510, 2012 